Author's reply: I thank Drs Arnone and Schifano for their letter, which opens the debate about the undeniable dangers of recreational drug misuse, compared with the relatively safe clinical use of MDMA. This topic has received considerable media interest, with particular attention centred on the damaged brains of users of ecstasy - an illegal compound, which may or may not contain varying amounts of MDMA, together with any other substance. Ecstasy is usually taken in combination with other illegal drugs (Curran, 1998) or large amounts of alcohol, and often in circumstances involving high temperatures, which are known to exacerbate neurotoxicity (Malberg \& Seiden, 1998).

All studies referred to by Drs Arnone and Schifano involve either recreational ecstasy users (mostly with no controls for other illegal drugs) or animal models with high and frequent dosage regimes that do not relate to those used for medically supervised MDMA psychotherapy research. The approach is therefore analogous to opposing the controlled, clinical research of opiate drugs after quoting studies of the morbidity of illegal heroin users.

Physiological studies involving infrequent and moderate doses of pure MDMA (as used in the psychotherapeutic setting) consistently demonstrate that the drug causes insignificant neurotoxicity, neuropsychological, mood or memory effects (Ludewig et al, 2003; Halpern et al, 2004).

Of course, there are risks when using any treatment-even in a controlled setting. All drugs, from paracetamol to cancer chemotherapy, are potentially harmful and must only be used after considering the risks and benefits - which includes considering the risk of doing nothing.

In relation to the opening comments, as a working psychiatrist, far from being 'repulsed' by neurobiological psychiatry, I am acutely aware of the importance of a holistic approach. Indeed, psychedelic psychotherapy, and the complexity of issues it raises, is a startling example of the effective interplay of concurrent psychological and organic treatments.
Given their history, MDMA and the other psychedelics are contentious treatments. However, it is possible for psychiatrists to think creatively and also consider safety and realistic risk-benefit ratios.

After all, if these compounds do have the potential to improve the speed and depth of psychotherapy, then they at least deserve clinical research in order to establish whether they can be useful tools to fight the global burden of neurotic illness.

Curran, H.V. (1998) 'Ecstasy': a Human Neurotoxin? A Novartis Foundation Meeting. http: / /www.ecstasy.org/ info/novartisl.html

Halpern, J. H., Pope, H. G. Jr, Sherwood, A. R., et a (2004) Residual neuropsychological effects of illicit 3,4methylenedioxymethamphetamine (MDMA) in individuals with minimal exposure to other drugs. Drug and Alcohol Dependence, 75, 149-152.

Ludewig, S., Ludewig, K., Hasler, F., et al (2003) No lasting effects of moderate doses of MDMA (Ecstasy) on memory performance and mood states in healthy humans. Biological Psychiatry, 53 (suppl.), 2055.

Malberg, J. E. \& Seiden, L. S. (1998) Small changes in ambient temperature cause large changes in 3,4methylenedioxymethamphetamine (MDMA)-induced serotonin neurotoxicity and core body temperature in the rat. Journal of Neuroscience, 18, 5086-5094.

B. Sessa The Park Hospital, Old Road, Headington, Oxford OX3 7LQ, UK. E-mail: drbensessa@hotmail.com

\section{Biology and stigma}

We wish to offer a brief response to the article by Drs Angermeyer and Matschinger (2005) entitled 'Casual beliefs and attitudes to people with schizophrenia'.

Underlying all forms of discrimination, including psychiatric stigmatisation, is an exaggerated attribution of 'otherness' to certain individuals or groups, so that there is an assumption (made by the discriminator) of the existence of fundamental differences between himself and 'the other'. Be it in the area of criminology, race, morality or mental health, this myth is further reinforced by the use of historically and culturally determined dichotomous constructs such as good/evil, citizen/alien, sane/insane and normal/ pathological. The association of a biological marker with any stigmatised group acts as a signifier, further emphasising that group's distinctiveness. Previous attempts to elucidate biological markers in criminals and in certain ethnic groups have served only to etch this mistaken notion of fundamental difference a little deeper in the mind of the discriminator and, in doing so, to reinforce prejudice. We believe that the findings of Angermeyer \& Matschinger may be partly explained through a similar effect following the promulgation of a biological theory of schizophrenia.

Cognitive-behavioural therapists address this myth of difference as a therapeutic strategy when working with people with psychosis by emphasising the continuity of symptoms across the range from those designated as 'sick' to 'normal' (Kingdon $\&$ Turkington, 1994). We believe that the extension of such an approach in the wider treatment of society could have a powerful role to play in the ongoing campaign against psychiatric stigmatisation. The origins of our current unsatisfactory conceptualisation of mentally ill people as being separated from 'normal people' by an absolute and fundamental boundary are often attributed to the Kraepelinian model. We welcome then the predictions made by Craddock \& Owen (2005) of the imminent demise of this in favour of a newer, hopefully less iatrogenic paradigm.

Angermeyer, M. C. \& Matschinger, H. (2005) Causal beliefs and attitudes to people with schizophrenia. Trend analysis based on data from two population surveys in Germany. British Journal of Psychiatry, 186, 331-334.

Craddock, N. \& Owen, M. J. (2005) The beginning of the end for the Kraepelinian dichotomy. British journal of Psychiatry, 186, 364-366.

Kingdon, D. G. \& Turkington, D. (1994) CognitiveBehavioural Therapy of Schizophrenia. New York: Guilford Press.

T. B. Benning, M. O'Leary, E. A. Avevor,

E. D. Avevor Department of Psychiatry, Doncaster Royal Infirmary, Armthorpe Road, Doncaster DN2 5LT, UK. E-mail: tonybbenning@hotmail.com 